\title{
Regional Woody Biomass Supply and Economic Impacts from Harvesting in the Southern U.S.
}

\section{Introduction}

Demand for woody biomass from southern forests is increasing due to interests in meeting the Renewable Fuel Standard (RFS), technology advances in co-firing and biomass conversion, overseas demand for wood pellets, and the prospects of expanding economic opportunities (Perez-Verdin et al., 2008; English et al., 2009; Hodges et al., 2010; Hodges et al., 2012). The U.S. Department of Agriculture (USDA) projected that $50 \%$ of the 21 billion gallons of advanced biofuels will be produced in the southeastern United States (US). The southern US has comparative advantage in producing bioenergy feedstocks, including soybean oil, energy cane, biomass sorghum, perennial grasses, and woody biomass (United States Department of Agriculture (USDA), 2010). In 2012, about $12 \%$ of electricity generation in the US was from renewable energy sources (U.S. Energy Information Administration (EIA), 2014).

More than $60 \%$ of current biomass-powered electricity generated in the US is from highly efficient Combined Heat and Power (CHP) applications. ${ }^{1}$ The success of any biomassdependent CHP project depends on the supply of appropriate biomass feedstock including forest residue, wood wastes, crop residue, energy crops, manure biogas, and urban waste (US Environmental Protection Agency; USEPA, 2007). Use of biomass for power generation is expected to double every 10 years through 2030 (U.S. Energy Information Administration (EIA), Energy Outlook 2009).

Forest resources are important economic assets of the southern US (Abt, 2013). Forestbased industries and local economies are closely integrated in regions heavily dependent on

\footnotetext{
${ }^{1}$ Major advances in drop-in fuel conversion technologies and biorefinery commercialization are also expected in the near future. For example, in 2014, Cool Planet Energy Systems began constructing its first commercial facility. The facility applies advanced technology converting woody biomass into fuels and biochar with a negative carbon footprint. So-called "green fuels" can be blended directly into the current fuel supply thereby reducing greenhouse gas emissions without sacrificing performance or increasing pump prices (Bioenergy News, 2014).
} 
logging, furniture and paper manufacturing. A 2008 economic impact analysis found that woodrelated manufacturing contributed to $8 \%$ of all manufacturing income and $10 \%$ of all manufacturing employment in the region (Abt., 2011). The 2005 to 2010 economic recession had substantial negative effects on the forest and logging industry in the southern states.

Development of wood-based bioenergy provides new growth opportunities for the forestry sector in this region (Hodges et al., 2012). A good example is the potential role of the wood pellet industry. Spelter and Toth (2009) estimated an increase of 1,855 jobs at a production level of 1.8 million metric tons of pellets in the southern US. Since 2012, the southern region has become the world's largest exporter of wood pellets. It is expected that annual wood pellet production in the South could reach more than 8 million tons by 2016 (Forest2Market, Inc, 2015). However, woody biomass is most economical as a fuel source when CHP systems or conversion facilities locate near fuel feedstock sources. Expansion of woody biomass supply may increase economic activity at sites attracting woody biomass bioenergy processors and the surrounding areas where woody biomass is harvested.

The southern US has abundant timber forest resources and reliable sources of woody biomass supply. According to the Forest Inventory Analysis (FIA) database, there are more than 100 million acres of hardwood, 60 million acres of softwood, and 20 million acres of mixed wood growing in this region. The total volume of all live trees in the region is about 279 billion cubic feet. Privately owned timber land comprises a significant portion of the total timber area (Smith et al., 2009). Potential woody biomass for energy production could be composed of logging residues, non-merchantable trees, or merchantable pulpwood trees. Most of these woody biomass energy feedstock sources will likely originate from private timberland (Perlack et al., 2005). These materials are more sensitive to price changes compared to urban wood waste and mill residues (DOE, 2011). Currently, only about $27 \%$ of the renewable energy consumed 
annually originates from wood and wood-derived fuels. Most of this energy is heat or electricity produced onsite using pulp and paper mills residues (White, 2010). The establishment of the USDA's Biomass Crop Assistance Program in 2008, along with other state policies, encourages the production of liquid fuels from woody biomass and wood-based electricity generation (Aguilar, Song, and Shifley, 2011). In addition, forest products are now included in the Biomass Markets Program in the Agricultural Act of 2014, providing further incentives to pellet and woody biomass industries to establish and expand supply capacity.

This research investigates three questions: (1) how much woody biomass is available to meet RFS mandates at given prices while meeting future conventional wood demand; (2) what is the geographic distribution of woody biomass supply based on location, species, and sources; and (3) how will woody biomass supply expansion impact jobs and total industry output at disaggregated regional levels in the southern US. A linear programming model of the forest sector, SWBioS, and a regional economic modeling system, IMPLAN, are bridged to accomplish these objectives.

\section{Research Context}

Studies quantifying woody biomass supply in the southern US and concomitant regional economic impacts are limited. In the 'Billion-Ton Study' by Perlack et al. (2005), and later Mendell et al. (2010), the availability and sustainability of woody biomass resources for energy production was analyzed at an aggregate national level, but woody biomass locations (or where these woody biomass will be harvested and collected) were not reported. The revised 2011 'Billion-Ton Update' addressed shortcomings of previous studies by estimating woody biomass supply under different scenarios at a higher geographic resolution than the first Billion Ton Study (U.S. Department of Energy (DOE), 2011). Milbandt (2005) used the Forest Inventory and 
Analysis (FIA)'s 2002 Timber Products Output (TPO) data at the state level to determine logging residue supply from commercial harvest activities and pre-commercial thinning operations based on how much wood was extracted annually and the amount of residue left on plots.

Geographically downscaling this information may be useful for generating more accurate estimates where biomass supply might originate.

Harvesting costs vary widely depending on the location of standing wood. Even if harvesting costs are low, there may not be enough harvestable material to support a biofuel plant. At the same time, not all the harvestable material can be extracted if harvesting costs are high. Understanding the economic feasibility of woody biomass harvest and transport is critical for determining the economic geography of woody biomass supply potential. Current national models either use technical engineering calculations with hypothetical future prices or survey data. Analyses are generally limited with respect to the economic feasibility of harvesting woody biomass.

A major question is also whether woody biomass demand for energy, in addition to conventional wood product demand, places significant pressure on long-term forest health and supply reliability. Concern centers on the types of woody biomass needed for energy production, and the impacts additional demands may have on forest ecosystem sustainability. Most logging residue currently are not collected as energy feedstock, but left on the field (plots) as land cover. If $70 \%$ of these residues, as suggested by Dahlberg et al. (2011), were collected as energy feedstock, the impact on forest sustainability may be negligible. However, the impact on forest inventory and the conventional wood-use sector may be significant if the bulk of woody biomass for energy production is from standing wood, including commercial sized pulpwood trees (Galik et al., 2009; Abt and Abt, 2013). Many studies have focused on logging residues as primary woody biomass sources (Perlack et al., 2005; Gan and Smith, 2006; U.S. Energy Information 
Administration (EIA), 2007; Perez-Verdin et al., 2009; Creech et al., 2009; Wu et al., 2011), but the combination of residue and standing wood as feedstock sources may become increasingly important once the limitation of relying on forest residues only is recognized (Galik et al., 2009; Morgan, 2009; Cputo, 2009; Munsell and Fox, 2010; Abt and Abt, 2013). Nearly 70\% of existing woody biomass feedstock currently originates from privately owned timber land (Smith et al., 2009). The amount of harvested biomass feedstock is substantially less than annual forest growth rates, suggesting roundwood as a potential woody biomass source (Smith et al., 2009). Nonetheless, it is important to determine the long term capacity of the nation's forest resources to address industry and ecosystem sustainability questions in terms of forests simultaneously meeting conventional and energy feedstock demands.

The study area of this research includes 13 southern states: Alabama, Arkansas, Florida, Georgia, Kentucky, Louisiana, Mississippi, North Carolina, Oklahoma, South Carolina, Tennessee, Texas, and Virginia. This regional definition is consistent with the US Forest Service's region in the report of Forest Resources of the United States, 2007 (Smith et al., 2009). These 13 states are composed of 79 Bureau of Economic Analysis (BEA) regions. The BEA areas group contiguous counties that are economically integrated (Figure 1), with the resulting area serving as a well-defined economic region. Not all BEAs are located inside state borders. Some BEA boundaries span several states due to metropolitan statistical area definitions. The BEA regions overlapping state borders were proportionally disaggregated to sub-BEAS according to the area a BEA covered in a state. For example, if a BEA region overlapped the border of two states, the BEA area was disaggregated into two sub-BEAs. In this research, BEA (if the BEA was entirely contained within a state) and sub-BEAs were used as units of analysis for estimating woody biomass supply. Results are reported at the BEA level. Thus supply estimates corresponding with sub-BEAs are aggregated back up to their respective BEAs. 


\section{$<<$ Figure $1>>$}

\section{Methods}

Two models were used to a) estimate the marginal costs of supplying woody biomass to the energy sector, and b) estimate the economic impacts of woody biomass supply activities. A version of the Southern Woody Biomass Supply model (SWBioS) was used to forecast woody biomass supply, subject to policy targets and conventional demand requirements. The SWBioS is an optimization model that determines which sub-BEAs have comparative advantage with respect to woody biomass supply given demand, resource constraints, and costs. The IMpact analysis for PLANing (IMPLAN) model (Olson and Lindall, 1996) was subsequently used to determine the corresponding economic impacts at the BEA level across the region. IMPLAN is an input-output model developed to estimate the impacts of specific sectors of an economy on jobs, industry output and total value added to the economy. The combined systems are summarized in Figure 2, and discussed in detail below.

\section{$<<$ Figure $2>>$}

\subsection{SWBioS model}

The SWBioS model is a linear programming (LP) optimization model that minimizes the total cost of harvesting, chipping, and stumpage, subject to production target goals for conventional wood demand and demand for woody biomass used as energy feedstock, land suitability, timber growth, timber activity types, stand-size class, topography, and timber product types. 
The core of the SWBioS model follows the model developed by He et al. (2014) with a focus on southern states only. The SWBioS model is benchmarked to a baseline scenario that assumes annual timber growth and existing timber land are sufficient to meet conventional wood demand while providing woody biomass in the forms of residue and roundwood at sub-BEA levels. Woody biomass supply capacity constraints were applied and the maximum amount of timber land by wood types and species was allocated to conventional wood production prior to imposing woody biomass supply levels. Solving the baseline model generates an estimate of the annual production capacity of standing forests. Production capacity, along with annual forest growth, is subsequently used as a constraint for forecasting woody biomass supply. A more detailed description of the SWBioS model applied in this analysis follows.

\subsubsection{Baseline scenario: conventional wood demand only}

The objective of the baseline model is to minimize the total costs of conventional wood demand including harvesting (HarvCost) and stumpage costs (StumpCost). Harvesting costs include cutting and removal of timber and wood components. Stumpage costs are assumed to cover production costs plus returns to landowners. The objective function is:

$$
\min _{X_{i, j, m, n}} \sum_{i=1}^{94} \sum_{j=1}^{3} \sum_{m=1}^{5} \sum_{n=1}^{4} X_{i, j, m, n} Y_{i, j, m, n}\left[\operatorname{HarvCost}_{i, j, m, n}+\text { StumpCost }_{i, j, m, n}\right]
$$

where $X_{i, j, m, n}$ are decision variables referring to forest harvested acreage in primary production sub-BEA regions $i=1, \ldots, 94$ by stand-size class $j=1,2,3$. Large trees at least 11 inches diameter for hardwood and at least nine inches diameter for softwoods are classified as Large $(j=1)$; medium diameter trees at least five inches diameter and smaller than large diameter trees are 
classified as Medium $(j=2)$; and small diameter trees, which are less than five inches diameter, are classified as Small $(j=3)$. Large and Medium sized trees are merchantable trees. Small sized trees are generally non-merchantable, but may be used as fuel wood.

There are $m=1, \ldots, 5$ types of standing wood considered in the model: upland hardwood ( $m=1)$, lowland hardwood $(m=2)$, natural softwood $(m=3)$, planted softwood $(m=4)$, and mixed wood $(m=5)$. Final timber product yield is denoted by $Y$. In the baseline model, there are seven categories of final timber products indexed by $n(n=1, \ldots, 4)$ and $j(j=1, \ldots, 3)$. Final timber products are aggregated to conventional wood demands: hardwood sawlogs $(n=1)$ from Large-size timber $(j=1)$; hardwood pulpwood $(n=2)$ from Medium-size timber $(j=2)$ and Small-size timber $(j=3)$ and softwood sawlogs $(n=3)$ from Large size timber $(j=1)$; softwood pulpwood $(n=4)$ from merchantable Medium-size timber $(j=2)$ and nonmerchantable small size timber $(j=3)$.

There are two key constraints in the baseline model: land and demand for conventional wood. The land availability and timber demand constraints are respectively:

$$
\sum_{n=1}^{4} X_{i, j, m, n} \leq L_{i, j, m}
$$

$$
\sum_{i \in \text { state }} \sum_{j=1}^{3} \sum_{m=1}^{4} X_{i, j, m, n} Y_{i, j, m, n}+\beta_{n} \sum_{i \in \text { state }} \sum_{j=1}^{3} \sum_{m=5}^{5} X_{i, j, m, n} Y_{i, j, m, n} \geq Q_{n, \text { state }}
$$

where $L$ is the available forest acreage in region $i$ of stand-size $j$, tree type $m$, and final product $n$. State level demand for conventional wood products is exogenous $\left(Q_{n, \text { state }}\right)$. The yield proportions of hardwood and softwood are identified by the proportional factor $\beta_{n}$. For a timber stand to be 
classified as mixed wood, it must contain between 25 and 50\% hardwood trees. The midpoint $(37.5 \%)$ is used in this analysis, and is determined by $\beta_{n}$ (37.5\% for hardwoods and $62.5 \%$ for softwoods). Therefore, mixed wood proportionally contributes to hardwood by $37.5 \%$ of yield and softwood by $62.5 \%$.

The baseline model was solved, absent woody biomass harvesting activities. The baseline solution provides the minimum forest acreage required to meet conventional wood demand. The constants $\bar{X}_{i, j, m, n}$ denote this solution. Along with the corresponding woody and residue yield, $\bar{X}_{i, j, m, n}$ is subsequently used to calculate the volume of harvestable trees used in the second stage of model calibration. Equation (4) summarizes this step:

$$
\bar{G}_{i, j, m}=\sum_{n=1}^{4} \bar{X}_{i, j, m, n} Y_{i, j, m, n}+g_{i, j, m}
$$

where $\bar{G}_{i, j, m}$ is the total available standing wood for harvest, and $g_{i, j, m}$ is an exogenous fixed growth rate for timber types.

\subsubsection{SWBioS model adjustments to include woody biomass activities}

Woody biomass originates from logging residue, non-merchantable and merchantable timber (Table 1). These materials are obtained from tree tops and branches only or from whole trees. In other words, a tree can produce only conventional logs with residue harvested as woody biomass, or both logs and tree tops collected as woody biomass. Residues can be collected from trees harvested to meet conventional demand. Among merchantable timber, there are different types of trees considered. 
$<<$ Table $1>>$

The SWBioS objective function is modified to include woody biomass production activities: collection logging residue, and harvesting whole merchantable and non-merchantable trees as energy feedstock.

$$
\underset{X_{i, j, m, n}}{\operatorname{Minimize}} \sum_{i=1}^{94} \sum_{j=1}^{3} \sum_{m=1}^{5} \sum_{n=1}^{6} X_{i, j, m, n} Y_{i, j, m, n}\left[\operatorname{HarvCost}_{i, j, m, n}+\operatorname{StumpCost}_{i, j, m, n}+\operatorname{ChipCost}_{i, j, m, n}\right]
$$

Compared to the baseline model, there are two additional final products in this model, including logging residue $(n=5)$ and small-size and medium-size whole trees harvested as woody biomass $(n=6)$. Therefore, in this modified model, $n=(1, \ldots, 6)$. Chipping costs (ChipCost) only apply to scenarios where whole trees $(n=6)$ are harvested as woody biomass.

\subsubsection{Woody biomass supply target constraints}

Three additional constraints were added to the baseline model with the modified objective function to analyze the harvesting options: minimum land requirements, harvest capacity constraints, and woody biomass production targets. The first two constraints used the $\bar{X}_{i, j, m, n}$ and $\bar{G}_{i, j, m}$ levels obtained from the baseline solution:

$$
X_{i, j, m, n} \geq \bar{X}_{i, j, m, n}
$$




$$
\sum_{m=1}^{5} \sum_{n=1}^{6} X_{i, j, m, n} Y_{i, j, m, n} \leq \bar{G}_{i, j}
$$

Equation (6) is a lower bound for forest land harvesting and ensures that woody biomass production does not impact conventional wood demands in region $i$. To ensure harvest sustainability, equation (7) constrains the production of conventional wood and woody biomass to be less than or equal to total standing wood available for harvest.

The woody biomass supply target constraint is:

$$
\sum_{i} \sum_{j} \sum_{m} \sum_{n} X_{i, j, m, n} Y_{i, j, m, n} \geq B Q
$$

where $B Q$ is the woody biomass supply target. The supply target is incrementally changed to obtain the corresponding shadow price $(\lambda)$ of supplying a target amount of woody biomass. The shadow price is the change in total costs, given an additional ton of woody biomass harvested. In a perfect competitive market, the shadow price is the per-unit price received for woody biomass. Woody biomass supply curves were estimated by incrementally increasing $B Q$ from 0 dry tons (OM) up to 140 million dry tons ( $140 \mathrm{M})$ using 1 million ton increments. The corresponding shadow prices for each increment proxy the supply price. Feedstock transportation costs of the feedstock from landing to facilities were not included in the model. The supply curves therefore represent the cost of materials delivered to the landing but not to biorefineries.

Other key assumptions are: a) only private industrial and non-industrial timberland with a slope of $30 \%$ or less are used to supply conventional wood products and woody biomass; b) harvested land remains in the same forest type; c) there are no yield increments over time. Short rotation woody crops are not included in the analysis because the 20 year period analyzed is 
relatively short, implying that harvested land will remain in the same forest type over time ${ }^{2}$; and d) woody biomass yields and growth rates $^{3}$ are held constant over the 2010-2030 period ${ }^{4}$.

\subsubsection{Scenarios with respect to woody biomass sources}

Three scenarios were considered for sources of woody biomass: 1) SLGR: only logging residue can be harvested as woody biomass; 2) $S L R N$ : logging residue and non-merchantable timber can be harvested as woody biomass to meet the supply target; and 3) SALL: medium size hardwood and softwood can be harvested as woody biomass in addition to logging residue and non-merchantable timber. Marginal cost curves (i.e., industry supply curves) were estimated under each scenario using the $0-140$ million dry ton scale at 1 million ton increments.

\subsection{Regional economic impact and the IMPLAN model}

The regional economic impact analysis uses the IMPLAN Version 3.1 modeling system and associated datasets for 2010 (Minnesota IMPLAN Group, Inc. 2010). IMPLAN is a wellestablished economic input-output model used to project economic impacts generated by variety of drivers at the national, state, regional, and county level. The national input-output dollar flow table, the Social Accounting Matrix (SAM), is at the core of the model. The SAM maps economic relationships between government, industry, and household sectors, allowing IMPLAN to model industry production activities (such as woody biomass harvesting). A series of SAM multipliers for a county or a group of counties (such as BEA) were generated in IMPLAN using national industry production data and functions combined with county-level

\footnotetext{
${ }^{2}$ Allowing for land transfers between cropland and forest land could be integrated into the model. However, information on future productivity from land used changes needs further research before this is possible.

${ }^{3}$ As defined by the Forest Inventory Analysis Database, growth rates exclude harvested plus dead trees.

${ }^{4}$ There is no increased rate of productivity gain assumed in the analysis. Growth rates remain constant as estimated from the Forest Inventory Analysis Database.
} 
economic data. The multipliers measure the amount of total economic activity resulting from an industry (or household) spending an additional dollar in the local economy. Based on these multipliers, IMPLAN generates spending impacts on gross receipts or output across industries as direct, indirect, and induced impacts. With each impact measure, IMPLAN generates estimates for changes in employment (including full time and part-time jobs), labor income, total industry output (TIO), and total value added (TVA) to the economy (Figure 2). TIO is the industry's total value of production, and TVA is the difference between the total output and the costs of intermediate inputs. In other words, value added is the industry's gross contribution to a region's entire economy.

The IMPLAN model contains more than 400 sector activities including harvesting whole trees or collecting and chipping wood residues from conventional logging as woody biomass. Conventional logging already exists in the IMPLAN model, but the cost information of collecting and chipping logging residue were needed to specify woody biomass harvesting activity since this is considered a new activity in the model. Operating cost shares on machine purchase, capital costs, maintenance and repairs, fuel and lube, labor salary, and fringe labor costs from Jernigan et al. (2013) were used to budget the activity of collecting and chipping logging residue.

IMPLAN's built-in economic multipliers measure the forest sector's direct, indirect, and induced economic impacts on the regional economy. Two types of activity multipliers were generated: 1) collecting and chipping logging residue multipliers, and 2) logging multipliers. If woody biomass originated from logging residue, multipliers for collecting and chipping activities were used. Logging multipliers were used if the whole trees were harvested as woody biomass. All estimated dollar values were converted to 2012 dollars. Impacts associated with each supply/harvesting scenarios are compared, focusing on changes in TVA, TIO, employment, and 
labor income (LI). The scenarios assume that woody biomass supplied from each BEA is used in the region due to the relatively high transport costs of raw woody material.

\section{Data Sources}

The LP model requires data on (1) timber land area; (2) annual volume of live tree growth per acre by forest stand type and geographic location; (3) merchantable and non-merchantable timber

products and residue yields; (4) harvesting costs, stumpage costs for harvesting different types of wood sources as woody biomass, and chipping costs (if tree boles are collected as feedstock); and (5) conventional wood demand. These data were acquired and developed from various sources, as follows.

Land available for harvesting a particular stand type (softwood, hardwood or mixed timber growing on slopes less or equal to 30\%) was estimated from the Forest Inventory and Analysis Data Base (FIA) (Woudenberg et al., 2010). Wood volume growth and timber yield data were estimated from the Forest Inventory and Analysis (FIA) database. The FIA data are recorded at plot levels, but are generally accessible at the county level. The US Forest Service's annual inventory assesses the extent, condition, volume, growth, and removal of timber in each state. The average annual net increase in the volume of trees during the period between inventories includes the incremental change in the net volume of trees reaching the minimum size class during the year, less the volume of trees that died during the year minus the net volume of trees culled during the year (Smith et al., 2009). Sawlogs (in cubic feet), pulpwood logs (in cubic feet), logging residues (in dry tons), and non-merchantable timber yields (in dry tons) were calculated based on the end product volume available for harvest on a per acre basis. Records were aggregated to three stand-size classes: (1) large stands if trees were at least 11 inches in diameter for hardwoods and nine inches in diameter for softwoods; (2) medium stands if trees 
were at least five inches in diameter; and (3) small stand sizes if trees were less than five inches in diameter (Woudenberg et al., 2010). This information was disaggregated to the 94 sub-BEA regions.

Forest harvesting costs, stumpage costs, and chipping costs (applying only to woody biomass harvesting from whole trees) were estimated for each of the 94 sub-BEA regions by wood and timber product types. Harvesting and chipping costs were obtained from the Fuel Reduction Cost Simulator (FRCS) harvest cost model (Dykstra, 2010). The US Forest Service provided the cost estimates of forest operations based on FIA plot data using the FRCS model (Skog, 2010). Costs include cutting and removing timber to log landings for solid wood products and chips, as well as the collection and chipping of branches as forest residues (Fight, Hartsough, and Noordijk, 2006). The three timber product categories recorded in the FRCS model are sawlogs, pulpwood, and woody biomass. Harvesting costs are categorized into each of the three groups (Table 2). The FIA plot data contains a mix of trees, and the cost estimates are calculated in terms of hardwoods, softwoods, and mixed woods (mixed stands of hardwood and softwood). The large stand-sized hardwood fraction was used to categorize the costs into these three forest types. A large stand-sized hardwood fraction of 0.5 to 1.0 was assumed to indicate hardwood, and a large stand-sized hardwood fraction of 0.2 to 0.4 was assumed to indicate mixed stands. Finally, the large stand-sized hardwood fraction between 0.0 to 0.19 was classified as softwood. A chipping cost of $\$ 6$ per green ton was assumed for whole trees harvested as woody biomass. Stumpage costs were obtained from Timber Mart-South third quarter 2013 report (Timber Mart South, 2013). Oklahoma and Kentucky were not reported in this data source. For this research, we used the Tennessee price for Kentucky and the Arkansas price for Oklahoma (Table 3). The stumpage costs for mixed wood were calculated as the weighted average of softwood $(62.5 \%)$ and hardwood $(37.5 \%)$ costs. 
$<<$ Table $2>>$

$<<$ Table $3>>$

Demand for conventional timber products was based on the United States Forest Products Model (USFPM), a sub-module of the Global Forest Products Model (GFPM) (Zhu et al., 2010). The USFPM uses a partial equilibrium mathematical program to project long-term annual forest product demand for the US at national and regional levels based on initial levels reported in the 2010 Resource Planning Act (RPA) Forest Assessment. Aggregate timber product demand was estimated for the Southern, Northern, and Western regions of the US. The demand target for aggregated timber products, including hardwood logs, softwood logs, and forest residues from 2010 to 2030 were determined using the USFPM projections for all forest products based on the Intergovernmental Panel on Climate Change (IPCC) scenario. Woody biomass use is primarily met by current pulpwood harvest; and it is assumed that current biomass for energy is included in wood demand. The USFPM data were adjusted because a portion of demand for wood products can be met by production from public forest land instead of private industrial and nonindustrial forest land. An adjustment factor of $3.03 \%$ for softwood and $2.59 \%$ for hardwood determine proportions that could be harvested from public forest land (Smith et al., 2009). The adjusted demand levels for conventional forest products are aggregated to sawlogs and pulpwood by hardwood and softwood (Table 4). In Table 4, pulpwood also includes demand for fuelwood which is mainly non-merchantable wood. Therefore, conventional demand is composed primarily of merchantable wood but includes a relatively small amount of non-merchantable wood. Production in each state must meet conventional demand first in the model. Excess supply is allocated to woody biomass demand. Proportional weights based on state annual timber 
harvest data projected by the US Forest Service were applied to disaggregate demand volumes to state levels (Howard, Quevedo, and Kramp, 2009; Kramp and Ince, 2010).

$$
<<\text { Table } 4>>
$$

\section{Results}

\subsection{Woody biomass supply and harvesting of roundwood}

Woody biomass supply curves for scenarios $S L G R, S L R N$ and $S A L L$ are presented in Figure 3. As demand for traditional roundwood products increases, the amount of residues available increases as evidenced by the rightward shift in the supply curves under SLGR and SLRN scenarios (Figure 3). Woody biomass from logging residue alone is limited; 38 million dry tons in 2020 at most at $\$ 50 /$ dry ton under $S L G R$. Under the $S L R N$ scenario, woody biomass can be supplied from non-merchantable trees, but costs increase as the biomass demand requirement increases due to their lower yields and limited availability. The total available woody biomass ranges from 41 million dry tons in 2015 to 52 million dry tons in 2030 at $\$ 103-\$ 105 /$ dry ton. To achieve the 42 million dry tons target in 2015, the woody biomass price could be as high as $\$ 187 /$ dry ton under the SLRN scenario.

\section{$<<$ Figure $3>>$}

Under the SALL scenario, supply curves shift leftward as demand for conventional wood products increases, indicating that more of the available woody biomass supply is needed to meet conventional demands over time. As additional conventional wood products are required by private industrial and nonindustrial timberlands from 2015 to 2030, woody biomass from logging 
residue becomes less expensive but non-merchantable timber become more expensive because of the limited availability of both woody biomass and traditional wood. ${ }^{5}$ The $S A L L$ scenario reflects the potential supply of wood available to meet woody biomass demand. Expanding what can be harvested for biomass, potential biomass supply increases to about 137 and 99 million dry tons in 2015 and 2030, respectively, at $\$ 199 /$ dry ton.

The increase in available residue over time results in lower costs required to meet greater biomass demand. A comparison of the scenarios for 2020 demonstrates the differences in biomass supply. Each scenario uses logging residues first because they are less expensive to harvest than whole non-merchantable and merchantable trees used for woody biomass. Logging residues provide up to 38 million dry tons of biomass at $\$ 45.49 / \mathrm{dry}$ ton. At this point, whole tree harvesting for woody biomass becomes competitive in terms of meeting a higher target at a lower price. Under the $S L R N$ scenario, non-merchantable trees along with logging residue provide total up to 39 million dry tons of woody biomass at $\$ 81.40 /$ dry ton. When no restrictions are placed on timber resources (SALL), supply expands to 72 million dry tons at the breakeven price of $\$ 49.82 /$ dry ton and 102 million dry tons at $\$ 60.35 /$ dry ton.

Scenarios $S L R N$ and $S A L L$ were examined to provide a profile of the impact that woody biomass harvesting might have at the breakeven roadside price ranges of $\$ 50-\$ 100$ per dry ton. Marginal values and the acres of medium sized standing tree harvested for woody biomass in 2020 for the scenarios are summarized in Table 5. This is a linear cost minimization program, and it is impossible to simulate a smooth supply curve with one million dry ton increments. We can only pick the points closest to $\$ 50, \$ 60$, and $\$ 100 /$ dry ton from each simulated curve as proxy breakeven prices for these scenarios and as a common reference for comparison. At the

\footnotetext{
${ }^{5}$ Note that the non-merchantable woods were also used to meet the conventional demand for fuel wood, which is categorized as pulpwood in this analysis.
} 
proxy price range of $\$ 50-\$ 80 /$ dry ton, 38 million dry tons of woody biomass in 2020 can be supplied under the $S L R N$ scenario. In this case, the price could be as high as $\$ 100 /$ dry ton if the supply targets increased to 39 million dry tons approximately. 72 million dry tons can be supplied under $S A L L$ scenarios at \$50/dry ton, which is composed of 38.48 million dry tons of logging residue and non-merchantable timber, 15.02 million dry tons of medium-size hardwood, and 21.06 million dry tons of medium-size softwood. About 0.78 million acres of hardwood, 1.20 million acres of planted softwood, 0.36 million acres of natural softwood, and 0.26 million acres of mixed wood in medium-size were harvested for woody biomass (Table 6). This amounts to less than $1 \%$ of the total annual available hardwood and softwood acreage. The medium size roundwood acreage harvested for woody biomass decreases over the study period in the $S A L L$ scenarios under the price of $\$ 60 /$ dry ton. This occurs because the supply amount decreases over time in this price range. Total woody biomass supply will not exceed 85 million dry tons in 2030 at the same price because of the relatively higher projected demands for conventional timber products.

$$
\begin{aligned}
& <<\text { Table } 5>> \\
& <<\text { Table 6>> }
\end{aligned}
$$

\subsection{Geographical distribution of woody biomass supply and corresponding economic impact at} the BEA regions

The geographic distributions of woody biomass supply volume (in millions of dry tons) were analyzed for the year 2020 at the breakeven price of $\$ 60 /$ dry ton (Figure 4). At $\$ 60 /$ dry ton, 38 million dry tons of woody biomass can be supplied under the SLRN scenario, wherein most of the feedstock are logging residue. Under the SALL scenario, 102 million dry tons can be supplied. 
Medium-size whole tree were the main contributors of woody biomass under the $S A L L$ scenario in some BEA regions.

$$
<\text { Figure } 4>>
$$

The woody biomass supplied by each BEA regions will likely be used in the region due to the high costs of transporting raw woody material. If a single biorefinery or co-firing plant in a BEA required 1,000 dry tons of woody biomass, the minimum demand per year in the region would be 0.36 million dry tons. Not all BEA regions can supply more than 0.36 million dry tons of woody biomass under the SLRN scenario in 2020. Many BEA regions in states including Oklahoma, Arkansas, Georgia, and Kentucky supply less than 0.36 million dry tons of woody biomass. Harvesting merchantable hardwood and softwood (medium-size standing trees) for woody biomass under $S A L L$ is required in some BEA regions to reach at least 0.36 million dry tons per year at $\$ 60 /$ dry ton.

\subsection{Economic impacts at the BEA and state level}

The corresponding economic impacts of woody biomass harvesting under SLRN and SALL for each BEA regions at $\$ 60 /$ dry ton are presented in Figure 5, including the Total Industry Output (TIO), Labor Income (LI), and Total Value Added (TVA) in millions of 2012 dollars. Comparing the BEA regions under $S L R N$, the volume of woody biomass harvesting affects TIO and TVA more than LI, which indicates that harvesting logging residue and non-merchantable tree for energy feedstock may increase local TIO and TVA. However, the impacts are limited by the capacity of available logging residue and non-merchantable tree. Labor income increases as well, but there is no difference across BEAs that supplied the logging residue. This could be 
because the labor requirement and costs for collecting logging residues are small. On the other hand, under the SALL scenario, TIO, LI, and TVA are varied across BEAs supplying different volume of woody biomass. This is because the labor costs and machine costs are much higher harvesting whole trees than collecting logging residue and harvesting non-merchantable timber alone.

Compared with $S L R N$, more BEA regions exhibited increases in TIOs from harvesting woody biomass that exceeded more than 10 million dollars under $S A L L$. This impact occurs because additional woody biomass can be supplied in these regions at $\$ 60 /$ dry ton. Some BEA regions in Alabama and South Carolina generated larger TIO, LI, and TVA exceeding 250 million dollars under the SALL scenario. Not all BEA economies will be uniformly affected by harvesting merchantable roundwood as woody biomass. Some BEAs remained the same or exhibited only minor changes in TIO, LI, and TVA because the supply for roundwood was relatively low at $\$ 60 /$ dry ton. If market prices are higher and more roundwood is available for non-conventional uses, these economies in these unaffected BEAs would be impacted.

Figure 6 presents the corresponding employment impacts of woody biomass harvesting at BEA level under the $S L R N$ and SALL scenarios in 2020. Allowing round wood harvesting for woody biomass increases employment in some regions, including west Tennessee, middle Alabama, southeast of South Carolina, and parts of North Carolina. Among these regions, more than 1,500 jobs are generated in the forest harvesting and related sectors. For BEA regions supplying only logging residue and non-merchantable timber, there were no significant changes in employment.

$<<$ Figure $5>>$

$<<$ Figure $6>>$ 
State level economic impacts on TIO, LI, TVA, and employment are summarized in Figure 7. Numbers in the figures are reported on a base 10 logarithmic scale. Under the SLRN scenario, the top five state economies that could be influenced most by harvesting logging residue and non-merchantable trees are South Carolina, Georgia, Mississippi, Alabama, and North Carolina. With merchantable roundwood available for woody biomass (the SALL scenario), there were more substantial positive changes in TIO, LI, and TVA in most of the southeast states, especially Florida and Kentucky. Changes in Louisiana are relatively small because the available merchantable roundwood is limited at $\$ 60 /$ dry ton. Most of these merchantable (medium-size) materials originate in South Carolina, Georgia, Mississippi, Alabama, North Carolina, Kentucky, and Florida. The ranking of economic impacts suggests that some states benefit more than others when merchantable roundwood is harvested as woody biomass. The same ranking occurs for changes in employment (Figure 7). Employment increased in all states, following job increases in South Carolina, Kentucky, Florida, Alabama, and North Carolina.

$<<$ Figure $7>>$

\section{Discussion and Conclusion}

Woody biomass could play an important role in the southern US for meeting the Renewable Fuel Standard because of its relatively low price and reliable supply. Developing this sector could have significant economic impacts in regions dependent on the forestry sector. However, expansion of woody biomass production and its use for bioenergy production could increase pressure on regional forestry management resources and at the same time bring economic benefits to regions depending on what materials are harvested and the location of harvesting 
activities. It is therefore important for policy makers and stakeholders to balance wood harvesting activities with forest ecosystem functions. Understanding these trade-offs requires knowledge of what types of woody biomass are available, the costs of extraction, and the degree to which this sector could impact local economies.

This research combined a linear programming model of the forestry sector and regional economic impact model downscaled to the US Bureau of Economic Analysis level. The study quantified the amount of woody biomass that could be produced as energy feedstock at different marginal costs assuming that future conventional wood demand is satisfied. Woody biomass supply appears to be price-responsive and available over a wide price range. Woody biomass supply from logging residues is expected to increase over time because of increasing demand for conventional wood products. However, woody biomass would be less expensive if both nonmerchantable and merchantable timber (e.g., pulpwood) could be harvested when biomass demand requirements are relatively high. Sawlog grade merchantable timber (large-size standing trees) were never harvested as woody biomass in this analysis. However, this may not be the case when sawlog prices are low. Future research could identity thresholds at which the harvesting of large-size standing trees would occur.

The IMPLAN model was used to estimate the economic impacts of woody biomass supply for bioenergy at the BEA level based on harvesting costs and sector-specific economic multipliers. Woody biomass harvesting could increase employment and add value to regional economies, but the impacts are spatially heterogeneous. The magnitude of economic impacts also depends the size of trees that are harvested as energy feedstock and the regional availability of low cost wood.

Findings suggest that collecting forest residues and non-merchantable timber may provide the largest initial contribution in meeting dedicated energy woody biomass supply goals. 
However, non-merchantable timber will not be sufficient to meet energy demand at lower costs. To provide 38 million dry tons from 2015 to 2030 , there is little need to harvest nonmerchantable or merchantable wood for bioenergy feedstocks because existing forest logging residues are sufficient to meet national woody biomass demand requirements at a marginal value of less than $\$ 60 /$ dry ton. However, when regional harvesting capacity was examined, not all regions had the capacity to develop scalable energy production sourced solely from logging residues. A combination of logging residue and merchantable roundwood is needed to meet higher woody biomass demand requirements.

Based on the IMPLAN multipliers and input costs for harvesting different woody biomass resources at $\$ 60 /$ dry ton, harvesting merchantable roundwood will also generate larger economic impacts in some regions compared with only harvesting logging residue and nonmerchantable timber because merchantable roundwood requires more input costs in labor and machinery. With and without merchantable roundwood can make a significant difference in some BEA regions in South Carolina, North Carolina, and Alabama in terms of TIO, LI, TVA, and employment can be created, while the economy of Louisiana and southern Mississippi were relatively unaffected at the $\$ 60$ price range. The economic impacts are regional-specific given the availability and costs of supplying different types of woody biomass materials.

The methodology and information generated from this research may be useful for the regional management for woody biomass, such as woody biomass plantation development, implementing integrated forest management systems, and determining optimal bioenergy facility location. The differences among harvesting combinations of residues and roundwood presented may help value different policies targeting the economically efficient supply of woody biomass in a specific region. The linkage between price, quantity, harvestable forest types, and future conventional wood demand means that the potential of woody biomass as an energy feedstock is 
directly connected to future wood market prices and forest management objectives. The decision of what types and when to harvest woody resources as energy feedstock will inevitably affect the development of feedstock markets and vice versa. For example, woody biomass markets may encourage managers to harvest non-merchantable timber and planted softwood as woody biomass, suggesting that a woody biomass extraction policies should consider the distribution of available resources, the costs of accessing these resources, and forest regeneration plans that can yield additional forest products without offsetting other benefits provided by forest ecosystems. Policies targeting the establishment of bioenergy facilities that use woody biomass feedstock need to consider the types of woody biomass available and the sustainability of supply that a specific region can provide under functional ecological constraints.

There are important caveats to this research. The results are based on a set of assumptions which limit the generalizability of the findings. One limitation is that the study used roadside costs and does not include transport costs. Transport costs from harvested sites to bioenergy facilities are not included. Sourcing at cost-minimizing locations can have benefits, but estimating the local distribution of woody biomass supply or potential wood-shed is needed to arrive at a more accurate cost of woody biomass supply. Another limitation of this analysis are the assumptions pertaining to forest stand growth rates. Woody biomass growth was fixed to one year over a 20 year span. This scale may underestimate available wood resources. Therefore, the marginal prices of harvesting merchantable stands may be lower than the estimates of the current analysis. The present cost estimates are therefore conservative. Finally, more detailed information about stand growth rates is needed to fully quantify the growth dynamics of forest stands.

Development of harvesting woody biomass using variety of medium-size standing trees have a positive effects on the local economies, bringing with it employment opportunities to 
some BEA regions. In future studies, the bioenergy sector could be included in the analysis with information about technology innovation, optimal location, and biorefinary and co-firing plant capacity.

\section{References}

Abt, K.L.,R.C. Abt; C. Galik. "Effect of Bioenergy Demands and Supply Response on Markets, Carbon, and Land Use.” Forest Science 58(2012):523-539. 
Abt, K.L. "Employment and Income Trends and Projections for Forest-based Sectors in the U.S." In: Wear, David N.; Greis, John G., eds. 2013. The Southern Forest Futures Project: technical report. Gen. Tech. Rep. SRS-GTR-178. Asheville, NC: USDA-Forest Service, Southern Research Station. pp293-308.

Abt, R.C. and K.L. Abt. "Potential Impact of Bioenergy Demand on the Sustainability of the Southern Forest Resource.” Journal of Sustainable Forestry 32 (2013): 175-194.

Aguilar, F.X., N. Song, and S. Shifley. "Review of Consumption Trends and Public Policies Promoting Woody Biomass as an Energy Feedstock in the U.S." Biomass and Bioenergy 35 (2011): 3708-3718.

Bioenergy News. “Cool Planet to Start Building Renewables Plant.” Internet site: http://www.bioenergy-news.com/index.php?/IndustryNews?item_id=7486\#sthash.39sGux6B.dpuf (Accessed March 12, 2014)

Caputo, J. "Sustainable Forest Biomass: Promoting Renewable Energy and Forest Stewardship." Policy Paper, Environmental and Energy Study Institute (EESI), 2009. Internet site: http://www.eesi.org/files/eesi_sustforbio_final_070609.pdf (Accessed April 1, 2014)

Creech, D., E. Metzger, S. Putt Del Pino, D.D. Wilson. “Local Clean Power: Renewable Electricity Opportunities in the Southeast United States.” World Resources Institute (WRI) Issue Briefs. April 2009. Internet site: http://www.seealliance.org/PDFs/powerofefficiency_wri_seea2009-04.pdf (accessed November 5, 2013). 
Dahlberg, A., G. Thor, J. Allmér, M. Jonsell, M. Jonsson, and T. Ranius. "Modelled Impact of Norway Spruce Logging Residue Extraction on Biodiversity in Sweden.” Canadian Journal of Forest Research 41(2011):1220-1232.

Dykstra, D.P. Personal Communication. USDA Forest Service, Forest Products Laboratory. July 2010.

English, B., K. Jensen, J. Menard, D. De La Torre Ugarte. New Markets and Opportunities for Agriculture in Colorado, Florida, Kansas, and North Carolina: an Economic Analysis of a Federal Renewable Portfolio Standard. Bipartisan Policy Centre. October, 2009. Internet website: http://bipartisanpolicy.org/library/research/new-markets-andopportunities-agriculture-colorado-florida-kansas-and-north. (Accessed online November, 2009).

Forest2Market, Inc. “Q1 2015 Recap: Global Wood Pellet Demand Creates US Opportunities”. 2015. http://blog.forest2market.com/wood-pellet-demand-creates-opportunity (Accessed online June 21, 2016).

Fight, R.D., B.R. Hartsough, and P. Noordijk. Users Guide for FRCS: Fuel Reduction Cost Simulator Software. United States Department of Agriculture, Forest Service, Pacific Northwest Research Station. General Technical Report PNW-GTR-668, January, 2006. The FRCS software is a free download that can be obtained from the USDA Forest Service.

Galik, C.S., R.C. Abt, and Y. Wu. "Forest Biomass Supply in the Southeastern United States: Implications for Industrial Roundwood and Bioenergy Production.” Journal of Forestry 107(2009): 69-77. 
Gan, J. and C.T. Smith. "Availability of Logging Residues and Potential for Electricity Production and Carbon Displacement in the USA." Biomass and Bioenergy 31(2006): 623-630.

He, L., B.C. English, D. Ugarte, and D.G. Hodges "Woody Biomass Potential for Energy Feedstock in United States.” Journal of Forest Economics 20(2014) 174-191.

Howard, J.L., E. Quevedo, and A. Kramp. Use of Indexing to Update U.S. Annual Timber Harvest by State. United State Department of Agriculture. Forest Service. Forest Products Laboratory. Research Paper FPL-RP-653, 2009.

Hodges, D., A. Hartsell, C. Brandeis; T. Brandeis, J. Bentley "Recession Effects on the Forests and Forest Products Industries of the South.” Forest Products Journal 61(2012):614-624.

Hodges, A.W., T.J. Stevens, M. Rahmani. Economic Impacts of Expanded Woody Biomass Utilization on the Bioenergy and Forest Products Industries in Florida. Project final report, Florida Department of Agriculture and Consumer Service-Division of Forestry, February 3, 2010.

Jernigan, P., T. Gallagher, J. Aulakh, R. Tufts, and T. McDonald. Implementing Residue Chippers on Harvesting Operations in the Southeastern US for Biomass Recovery. International Journal of Forest Engineering. June 2013.

Kramp, A. and P. Ince. The U.S. Forest Products Module (USFPM): Forest Sector Modeling Using the GFPM with Global Wood Energy and U.S. Climate Change Scenarios. Internet site: 
http://www.nancy.inra.fr/lef/content/download/3244/32804/version/1/file/J_Buongiorno_ Kramp_3.pdf. (Accessed online August 20, 2010)

Mendell, B., A. Hamsley, T. Sydor, and S. Freeman. Availability and Sustainability of Wood Resources for Energy Generation in the United States. American Forest and Paper Association, June 2010.

Milbrantd, A. A Geographic Perspective on the Current Biomass Resource Availability in the United States. National Renewable Energy Laboratory, Technical Report, NREL/TP-560$39181,2005$.

Minnesota IMPLAN Group, Inc. “User's Guide to IMPLAN Version 2.0 Software.” Minnesota IMPLAN Group, Inc.: Hudson, WI, 2011.

Morgan, T.A. An assessment of forest-based woody biomass supply and use in Montana. Forestry Assistance Bureau, Forest Division, Montana Department of Natural Resources and Conversion, Missoula, Montana, 2009.

Munsell, J.F. and T.R. Fox. "An Analysis of the Feasibility for Increasing Woody Biomass Production from Pine Plantations in the Southern United States.” Biomass and Bioenergy 34(2010): 1631-1642.

Olson, D. and Lindall, S. "IMPLAN professional software, analysis, and data guide." Stillwater, Minnesota: Minnesota IMPLAN Group. 1996.

Perlack, R.D., L.L. Wright, A.F. Turhollow, R.L. Graham, B.J. Stokes, D.C. Erbach. Biomass as Feedstock for a Bioenergy and Bioproducts Industry: the Technical Feasibility of a 
Billion-ton Annual Supply. Oak Ridge National Laboratory, Oak Ridge, TN, DOE/GO102995-2135, 2005.

Perez-Verdin, G., D.L. Grebner, C. Sun, I.A. Munn, E.B. Schultz, and T.G. Matney. "Woody Biomass Availability for Bioethanol Conversion in Mississippi.” Biomass and Bioenergy 33(2009): 492-503.

Perez-Verdin, G., D.L. Grebner, I.A. Munn. "Economic Impacts of Woody Biomass Utilization for Bioenergy in Missisippi." Forest Products Journal 58(2008): 75-83.

Skog, K.E. Personal Communication. USDA-Forest Service, July 2010.

Smith, WB., PD. Miles, CH. Perry, and SA. Pugh (2009). Forest resources of the United States, 2007. Gen. Tech. Rep. WO-78. Washington, DC: U.S. Department of Agriculture, Forest Service, Washington Office. http://www.fia.fs.fed.us/program-features/rpa/ Accessed May 17, 2009.

Timber Mart South. "The Journal of Southern Timber Prices: A Brief, Easy-to-Read, Quarterly Report of the Market Prices for Timber Products of the Southeast.” $3^{\text {rd }}$ Quarter, 2013

U.S. Department of Agriculture (USDA). A USDA Regional Roadmap to Meeting the Biofuels Goals of the Renewable Fuels Standard by 2022. USDA Biofuel Strategic Production Report June 23, 2010.

U.S. Energy Information Administration (EIA). How Much U.S. Energy Consumption and Electricity Generation Comes from Renewable Sources? Internet site: http://www.eia.gov/tools/faqs/faq.cfm?id=92\&t=4 (Accessed online February 21, 2014). 
U.S. Energy Information Administration (EIA). Energy and Economic Impacts of Implementing Both a 25-percent Renewable Portfolio Standard and a 25-percent Renewable Fuel Standard by 2025. Washington D.C.: Department of Energy. May 2007.

U.S. Environment Protection Agency (EPA). Biomass Combined Heat and Power Catalog of Technologies' U.S. EPA Combined Heat and Power Partnership. Report prepared by: Energy and Environmental Analysis, Inc., an ICF International Company, and Eastern Research Group, Inc. (ERG) for the U. S. Environmental Protection Agency, Combined Heat and Power Partnership, September 2007.

U.S. Department of Energy (DOE). U.S. Billion-Ton Update: Biomass Supply for a Bioenergy and Bioproducts Industry. R.D. Perlack and B.J. Stokes (Leads), ORNL/TM-2011/224. Oak Ridge National Laboratory, Oak Ridge, TN. 227p, 2011.

Woudenberg, S.W., B.L. Conkling, B.M. O'Connell, E.B. LaPoint, J.A. Turner, K.L. Waddell. The Forest Inventory and Analysis Database: Database Description and User's Manual Version 4.0 for Phase 2. Fort Collins, CO: U.S. Department of Agriculture, Forest Service, Rocky Mountain Research Station. General Technical Report RMRS-GTR- 245, 2010.

White, E.M. Woody Biomass for Bioenergy and Biofuels in the United States - a Briefing Paper. United States Department of Agriculture, Forest Service, Pacific Northwest Research Station. General Technical Report PNW-GTR=825, 2010.

Wu, J., J. Wang, and J. McNeel. "Economic Modeling of Woody Biomass Utilization for Bioenergy and its Application in Central Appalachia, USA.” Canadian Journal of Forest Research 41 (2011):165-179. 
Zhu, S., J. Buongiorno, J.A. Turner, and R. Raunika. The Global Forest Products Model (GFPM). Internet site:

http://forestandwildlifeecology.wisc.edu/facstaff/Buongiorno/book/GFPM.htm (Accessed April 5, 2011) 


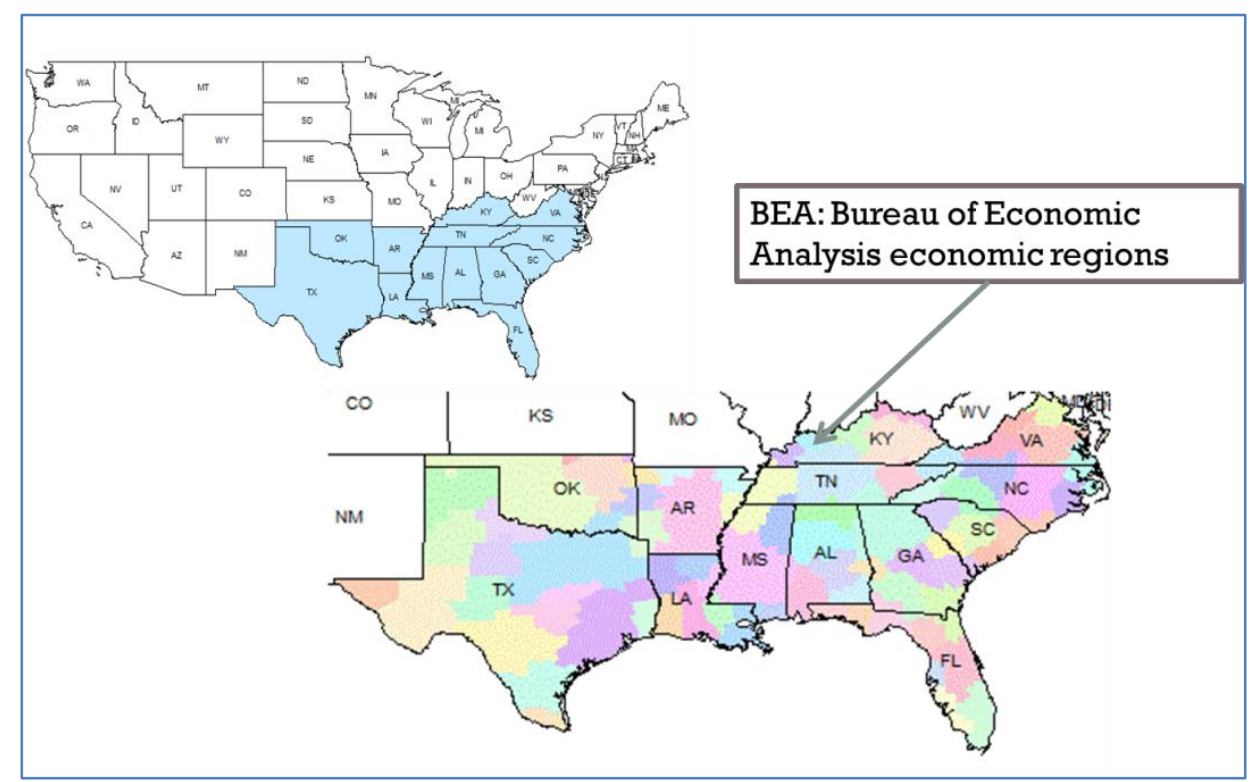

Figure1. Research area and geographic units 
IMPLAN

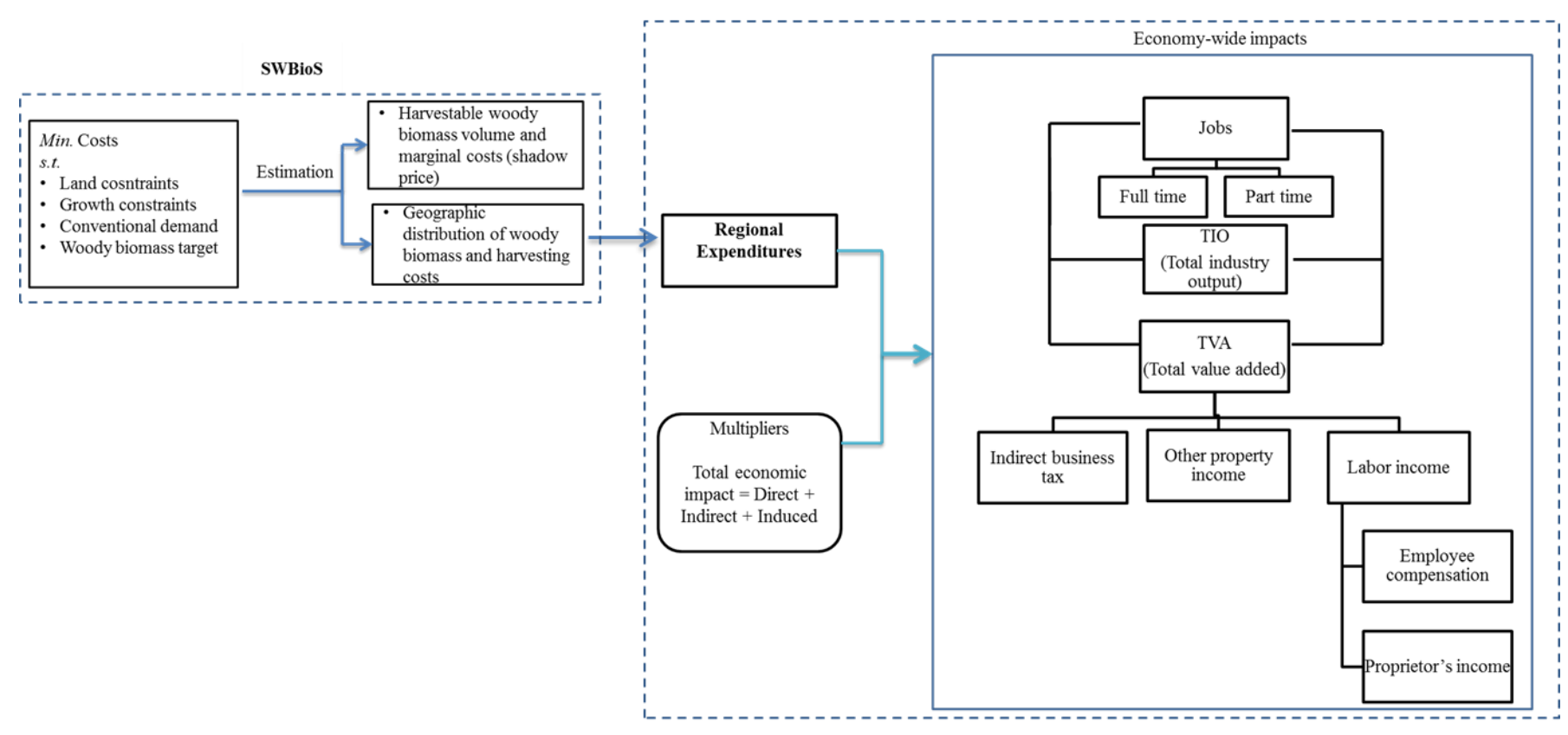

Figure 2.SWBioS and IMPLAN model work flow 
1

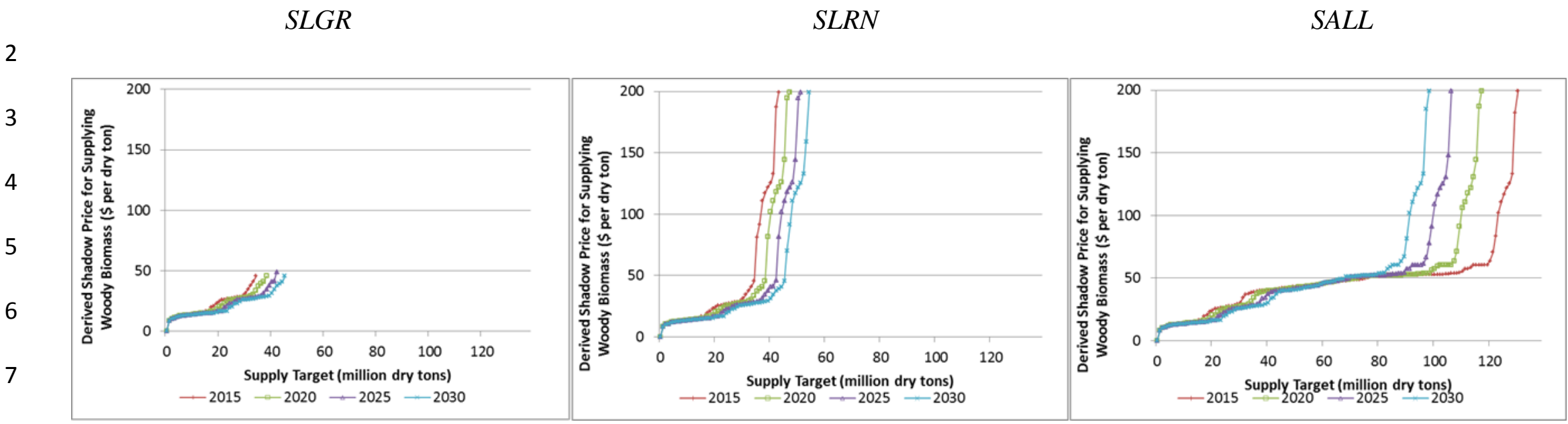

8

9

Figure 3. Woody biomass supply curves under SLGR, SLRN and SALL from 2015 to 2030.

10 
SLRN: 38 million dry tons

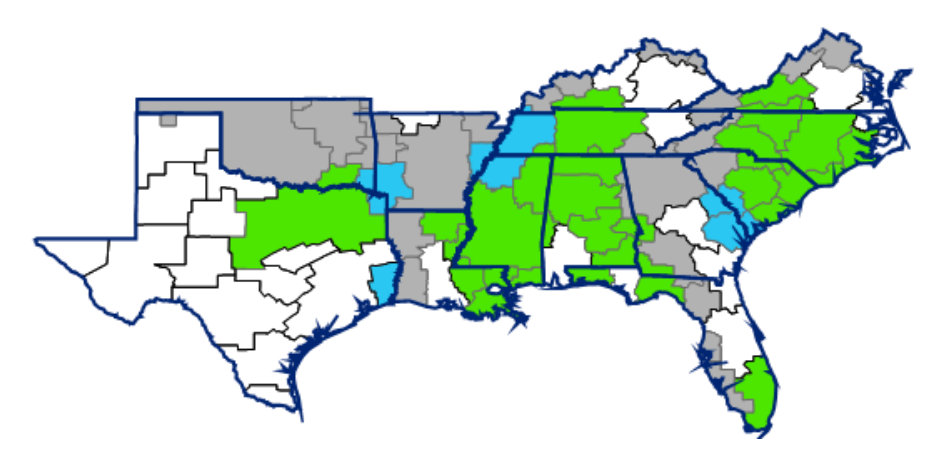

SALL: 102 million dry tons

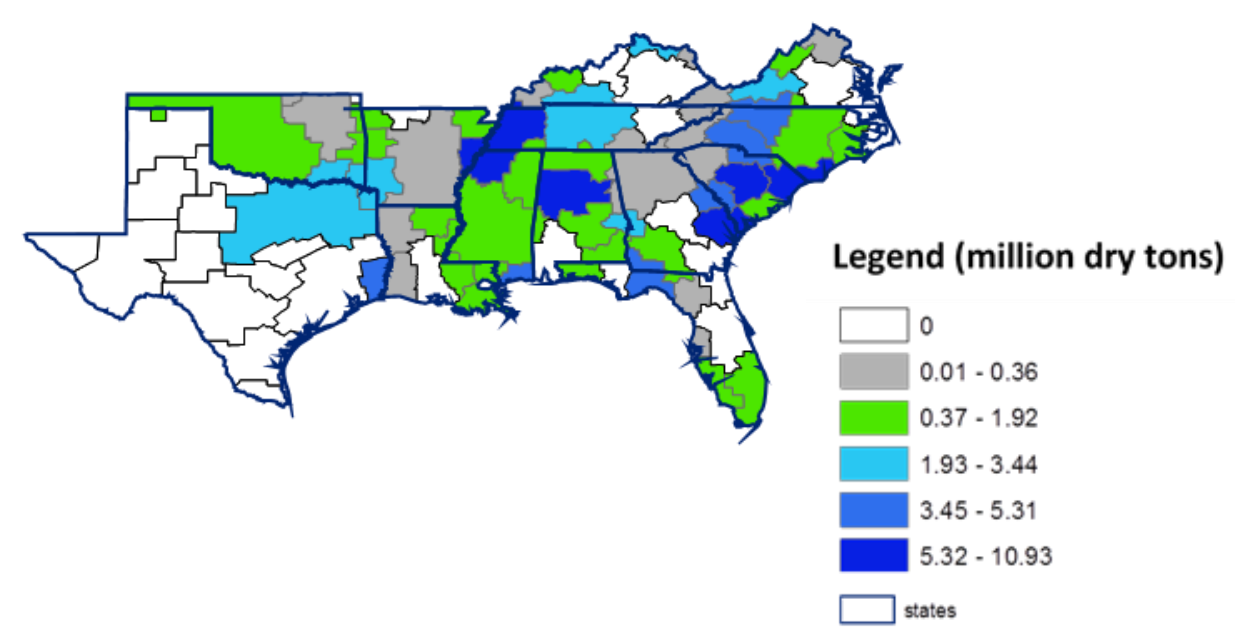

Figure 4. Woody biomass geographic distribution of maximum supply at $60 \$$ per dry ton in 2020 under scenario $S L R N$ and $S A L L$. 


\section{SLRN:}

38

million

dry tons
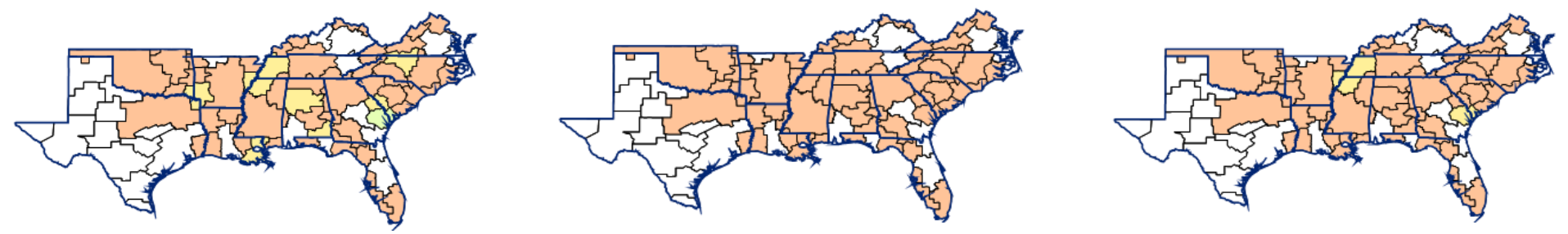

SALL:

102

million

dry tons
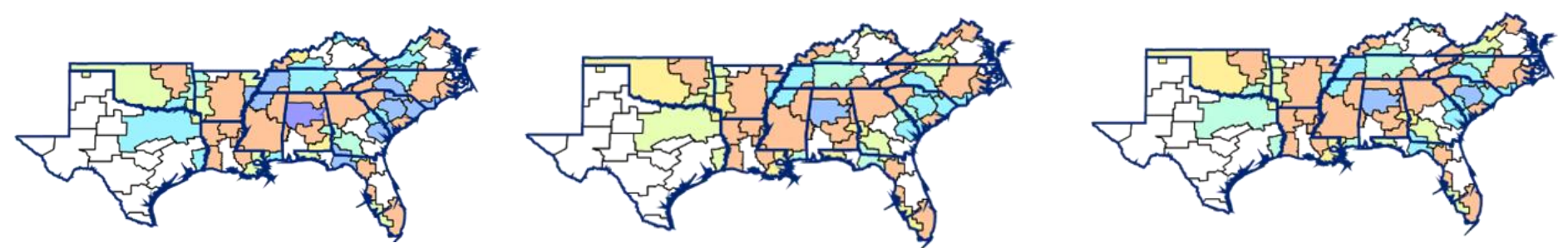

Legend (million \$)

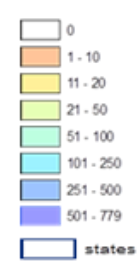

Figure 5. Economic impact at BEA levels; $60 \$$ per dry ton in 2020 under scenarios $S L R N$ and $S A L L$ 


\section{SLRN}

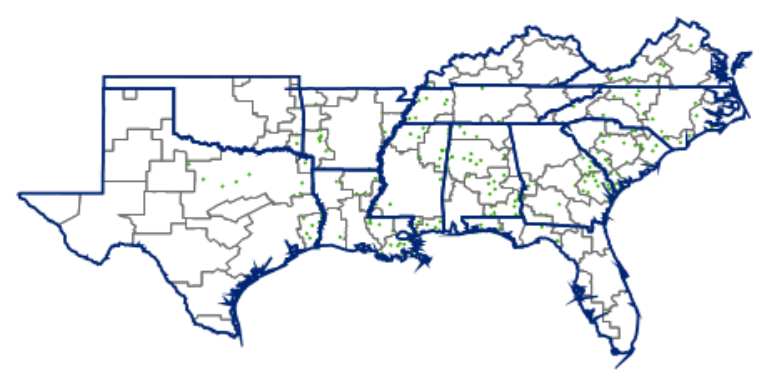

SALL

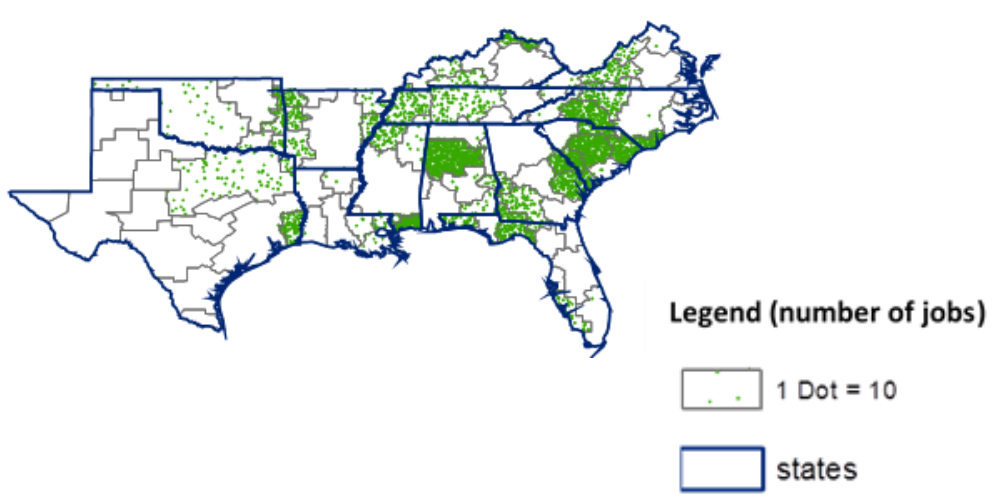

Figure 6. Employment impact of woody biomass harvesting at $60 \$$ per dry ton in 2020. 


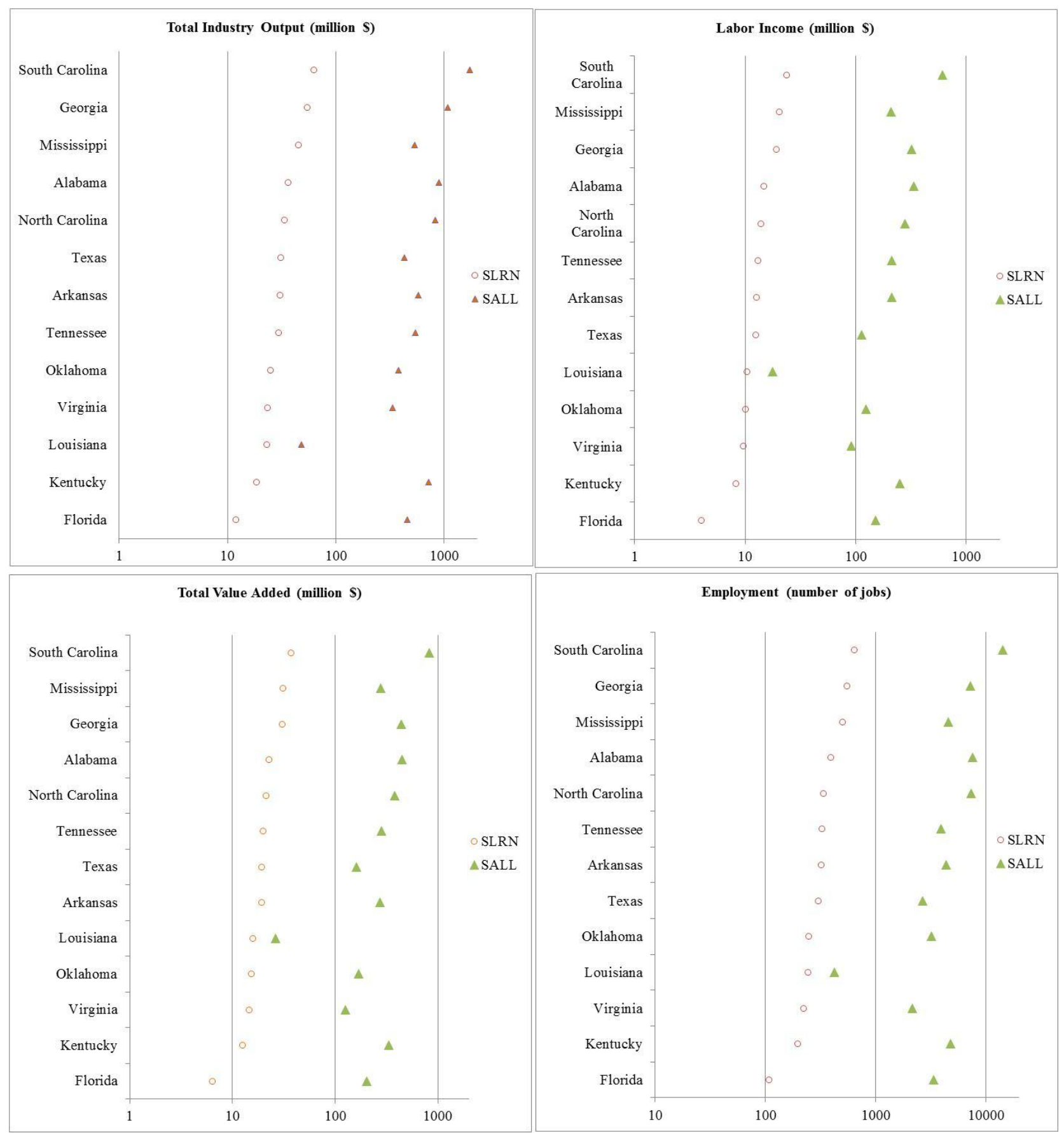

Figure 7 State level total industry output, labor income, total employments, and total value added; $\$ 60$ per dry ton in 2020 under SLRN and SALL scenarios, logarithmic scale (base 10) 
Table 1. Potential woody biomass sources

\begin{tabular}{ll}
\hline Sources & \multicolumn{1}{c}{ Description } \\
\hline Logging residue & Tops and branches from conventional logging \\
Non-merchantable timber & $\begin{array}{l}\text { Small-size round wood whole tree }(<5 \text { inches } \\
\text { stand diameter })\end{array}$ \\
Merchantable timber & $\begin{array}{l}\text { Medium-size hardwood }(5-11 \text { inches stand } \\
\text { diameter) and softwood }(5-9 \text { inches stand } \\
\text { diameter) }\end{array}$ \\
\hline
\end{tabular}


Table 2. Average regional harvesting costs for logs and residue (\$ per acre)

\begin{tabular}{lccc}
\hline Wood types & Logs & Residue & Chipping \\
\hline Hardwood & 843 & 41 & 192 \\
Softwood & 834 & 23 & 341 \\
Mixed wood & 939 & 33 & 225 \\
\hline
\end{tabular}


Table 3. Stumpage costs ( $\$$ per dry ton) by state, timber type, and stand size

\begin{tabular}{lrrrrrrrrrr}
\hline & \multicolumn{3}{c}{ Hardwood } & \multicolumn{3}{c}{ Softwood } & \multicolumn{3}{c}{ Mixed wood } \\
\cline { 2 - 11 } & Large & Medium & Small & Large & Medium & Small & Large & Medium & Small \\
\hline Alabama & 44.89 & 15.33 & 7.67 & 26.78 & 10.66 & 5.33 & 31.72 & 12.41 & 6.21 \\
Arkansas & 42.15 & 9.59 & 4.80 & 20.26 & 7.81 & 3.91 & 29.99 & 8.48 & 4.24 \\
Florida & 17.67 & 8.31 & 4.16 & 28.30 & 14.82 & 7.41 & 14.08 & 12.38 & 6.19 \\
Georgia & 35.19 & 8.86 & 4.43 & 25.59 & 10.71 & 5.36 & 26.58 & 10.02 & 5.01 \\
Kentucky & 38.33 & 9.48 & 4.74 & 16.33 & 7.35 & 3.68 & 23.86 & 8.15 & 4.07 \\
Louisiana & 36.42 & 9.77 & 4.89 & 25.03 & 8.81 & 4.41 & 29.89 & 9.17 & 4.59 \\
Mississippi & 46.25 & 11.77 & 5.89 & 23.79 & 8.69 & 4.35 & 34.43 & 9.85 & 4.92 \\
North & & & & & & & & & \\
Carolina & 35.59 & 4.79 & 2.40 & 25.36 & 8.39 & 4.20 & 23.49 & 7.04 & 3.52 \\
Oklahoma & 42.15 & 9.59 & 4.80 & 20.26 & 7.81 & 3.91 & 29.99 & 8.48 & 4.24 \\
South & & & & & & & & & \\
Carolina & 37.00 & 8.64 & 4.32 & 23.32 & 9.98 & 4.99 & 22.27 & 9.48 & 4.74 \\
Tennessee & 38.33 & 9.48 & 4.74 & 16.33 & 7.35 & 3.68 & 23.86 & 8.15 & 4.07 \\
Texas & 28.44 & 8.06 & 4.03 & 25.84 & 7.73 & 3.87 & 24.29 & 7.85 & 3.93 \\
Virginia & 34.83 & 5.36 & 2.68 & 23.52 & 12.15 & 6.08 & 21.13 & 9.60 & 4.80 \\
\hline Large: at least & 11.65
\end{tabular}

Large: at least 11 inches stand diameter for hardwood and at least 9 inches stand diameter for softwood;

Medium: at least 5 inches stand diameter and smaller than large stand diameter trees;

Small: less than 5 inches diameter; 
Table 4. Conventional demand for timber products from 2015 to 2030 for southern US

\begin{tabular}{lcccc}
\hline Timber product & 2015 & 2020 & 2025 & 2030 \\
\hline & \multicolumn{4}{c}{ million cubic feet } \\
Hardwood sawlog & 1247 & 1291 & 1341 & 1390 \\
Softwood sawlog & 3432 & 3685 & 3996 & 4283 \\
Hardwood pulpwood & 1770 & 1866 & 1975 & 2081 \\
Softwood pulpwood & 2591 & 3317 & 4001 & 4479 \\
\hline
\end{tabular}


Table 5. Estimated price ranges and woody biomass composition from different supply targets in 2020

\begin{tabular}{|c|c|c|c|c|c|c|}
\hline Scenarios & $\begin{array}{l}\text { Woody biomass } \\
\text { supply targets }\end{array}$ & $\begin{array}{c}\text { Shadow } \\
\text { price }\end{array}$ & $\begin{array}{c}\text { Price } \\
\text { category }\end{array}$ & $\begin{array}{c}\text { Logging residue \& } \\
\text { non-merchantable } \\
\text { timber }\end{array}$ & $\begin{array}{c}\text { Medium-size } \\
\text { hardwood }\end{array}$ & $\begin{array}{c}\text { Medium-size } \\
\text { softwood }\end{array}$ \\
\hline & million dry tons & $\$ /$ dry ton & $\$ /$ dry ton & \multicolumn{3}{|c|}{ million dry tons } \\
\hline$S L G R$ & 38 & 45.49 & 45 & 38 & $N A$ & $N A$ \\
\hline \multirow[t]{2}{*}{ SLRN } & 38 & 45.49 & $45-80$ & 38 & $N A$ & $N A$ \\
\hline & 39 & 81.40 & $81-100$ & 39 & $N A$ & $N A$ \\
\hline \multirow[t]{3}{*}{$S A L L$} & 72 & 49.82 & 50 & 38.48 & 15.02 & 21.6 \\
\hline & 102 & 60.35 & 60 & 38.48 & 40.63 & 28.76 \\
\hline & 109 & 91.37 & $90-100$ & 38.49 & 46.94 & 31.01 \\
\hline
\end{tabular}


Table 6. Comparison of total supply and harvested medium size standing wood (5-9/5-11 inches stand diameters) timber acreage for woody biomass at $60 \$$ per dry ton under scenario $S A L L$

\begin{tabular}{cccccccc}
\hline & $\begin{array}{c}\text { Marginal } \\
\text { price }\end{array}$ & Total Supply & LHW & UHW & PS & NS & MIXED \\
\cline { 2 - 8 } Year & \$perdry ton & $\begin{array}{c}\text { million dry } \\
\text { ton }\end{array}$ & \multicolumn{5}{c}{ million acres } \\
\hline 2015 & 60 & 114 & 0.22 & 0.62 & 1.72 & 0.4 & 0.26 \\
2020 & 60 & 102 & 0.18 & 0.6 & 1.2 & 0.36 & 0.25 \\
2025 & 60 & 93 & 0.15 & 0.56 & 0.74 & 0.35 & 0.25 \\
2030 & 60 & 85 & 0.12 & 0.51 & 0.44 & 0.29 & 0.24 \\
\hline
\end{tabular}

LHW: low-land hardwood; UHW: upper-land hardwood; PS: planted softwood; NS: natural softwood; MIXED: mixed wood. 